\title{
Clinical and prognostic association of oncogene cadherin 11 in gastric cancer
}

\author{
QIANG WANG ${ }^{1}$, YINGDONG JIA ${ }^{1}, \mathrm{XUDONG} \mathrm{PENG}^{2}$ and $\mathrm{CHUNHONG} \mathrm{LI}^{3}$ \\ ${ }^{1}$ Gastrointestinal Surgical Unit, Suining Central Hospital, Suining, Sichuan 629000; ${ }^{2}$ Gastrointestinal Surgical Unit, \\ The First Affiliated Hospital of Chongqing Medical University, Chongqing 400000; \\ ${ }^{3}$ Department of Oncology, Suining Central Hospital, Suining, Sichuan 629000, P.R. China
}

Received July 29, 2019; Accepted February 7, 2020

DOI: $10.3892 / \mathrm{ol} .2020 .11531$

\begin{abstract}
The abnormal expression of cadherin-11 (CDH11) affects the progression of several types of cancer. However, the expression pattern and prognostic value of CDH11 in gastric cancer (GC) have not been reported. In the present study, the expression of CDH11 in patients with GC and its effect on their survival were analyzed using public cancer databases. The expression of CDH11 in GC tissues was significantly higher compared with that in normal gastric tissues. The expression of CDH11 was higher in advanced GC compared with early $\mathrm{GC}$, and increased CDH11 was associated with tumor progression and poor prognosis in patients with GC. The high level of methylation in the promoter of CDH11 in GC tissues was not sufficient to reverse the upregulation of CDH11 caused by transcriptional activation. Finally, the expression pattern and prognostic significance of CDH11 in GC were validated using data from patients with GC recruited for the present study. Collectively, the present results demonstrated that CDH11 was upregulated in GC tissues, and suggested that high CDH11 expression may be associated with progression and poor prognosis in GC.
\end{abstract}

\section{Introduction}

In the last 30 years, advances in molecular biology have led to the development of molecular targeted therapy as an important and feasible approach to treat gastric cancer (GC). For example, trastuzumab, a monoclonal antibody against human epidermal growth factor receptor 2, and ramucirumab, a monoclonal antibody against vascular endothelial growth factor receptor 2 (VEGFR2), are used for the treatment of advanced GC $(1,2)$. However, despite a comprehensive treatment strategy based on surgery, chemotherapy, radiotherapy and molecular targeted

Correspondence to: Dr Chunhong Li, Department of Oncology, Suining Central Hospital, 127 Desheng West Road, Chuanshan, Suining, Sichuan 629000, P.R. China

E-mail: chunhongli19880205@163.com

Key words: cadherin-11, gastric cancer, prognosis therapy, the 5-year survival rate of patients with GC remains unsatisfactory. Therefore, it is necessary to continue searching for effective molecular therapeutic targets.

Cadherin 11 (CDH11) is a type II cadherin located on human chromosome 16q22.1 (3); its encoded protein, CDH11, contains an extracellular domain of five repeats, a single membrane-spanning domain and a highly conserved C-terminal cytoplasmic domain (4). CDH11 mediates cell-cell and cell-extracellularmatrix adhesion through $\mathrm{Ca}^{2+}$-dependent homophilic interactions. The role of CDH11 in cancer progression has attracted increased attention $(5,6)$. Chu et al $(7)$ have reported that $\mathrm{CDH} 11$ expression gradually increases from primary prostate cancer to metastatic lesions, particularly in the bone. The intracardiac injection of prostate cancer PC3 cells results in the formation of bone metastasis, which is inhibited by CDH11 knockout, in mice (7). Further mechanistic studies have revealed that $\mathrm{CDH} 11$ not only facilitates the physical link between cancer cells and osteoblasts through CDH11 homophilic interactions, but also increases the metastatic ability of cancer cells by promoting the expression of migration- and invasion-associated genes induced by the juxtamembrane and $\beta$-catenin binding domains of CDH11 $(7,8)$.

Assefnia et al (9)analyzed human cancer microarray datasets from The Cancer Genome Atlas (TCGA) and reported that $\mathrm{CDH} 11$ was increased in breast cancer and brain malignancy compared with normal tissues. In vitro assays revealed that CDH11 knockdown significantly inhibited the growth and metastasis of breast cancer and glioblastoma cells (9). Nakajima et al (10) demonstrated that patients with osteosarcoma and high expression of CDH11 exhibited significantly longer overall survival (OS) time compared with those with low CDH11 expression. Promoter $\mathrm{CpG}$ methylation is an important process of gene inactivation (11). Carmona et al (12) have demonstrated that the CDH11 gene in the lymphatic metastases of melanoma and head and neck tumors display notable methylation compared with primary tumors, resulting in the epigenetic silencing of CDH11. Cellular and mouse models have demonstrated that the restoration of CDH11 expression decreases the growth, motility and dissemination of metastatic head and neck cancer cells, whereas the depletion of CDH11 expression enhances growth and motility.

CDH11 is one of the 13 previously identified genes exhibiting significantly increased $\mathrm{CpG}$ methylation in GC compared 
with the non-metaplastic gastric mucosa (13). However, the role of CDH11 in GC progression remains unclear. The present study aimed to use public cancer databases to explore the expression pattern of $\mathrm{CDH} 11$ and analyze the potential function and prognostic value of CDH11 in GC.

\section{Materials and methods}

Patients and tissues. A total of 30 pairs of frozenGC and matched paracancerous tissues ( $\geq 6 \mathrm{~cm}$ away from the tumor) were collected from patients with GC (21 men and 9 women; mean age, 60.6 years; age range, 51-79 years) who were admitted to the First Affiliated Hospital of Chongqing Medical University (Chongqing, China) between June 2016 and October 2016. These samples were used for reverse transcription-quantitative (RT-q)PCR. Another 82 paraffin-embeddedpairs of GC tissues and matched paracancerous tissues were collected from patients with GC admitted to the First Affiliated Hospital of Chongqing Medical University between January 2011 and September 2014, which were used for immunohistochemical analysis. The patient cohort for immunohistochemistry comprised 55 men and 27 women with a mean age of 57.7 years (age range, 46-80 years). Tumor-Node-Metastasis (TNM) staging (14) was as follows: 14 cases of stage I, 28 cases of stage II, 35 cases of stage III and 5 cases of stage IV. All patients underwent total or subtotal gastrectomy for the first time and did not receive radiotherapy and chemotherapy prior to surgery. Of the 112 patients with GC, 21 cases were highly differentiated, 42 were moderately differentiated and 49 were poorly differentiated. The use of human tissue samples and experimental protocols were approved by the Medical Ethics Review Committee of the First Affiliated Hospital of Chongqing Medical University, and written informed consentwas obtained from all patients.

$R T-q P C R$. Total RNA was extracted from $30 \mathrm{mg}$ of frozen tissues using the TRIzol ${ }^{\circledR}$ reagent (Takara Biotechnology Co., Ltd.) and reverse-transcribed into cDNA according to the manufacturer's instructions. The reverse transcription conditions were as follows: $37^{\circ} \mathrm{C}$ for $15 \mathrm{~min}$ and $85^{\circ} \mathrm{C}$ for $5 \mathrm{sec}$. Two-step PCR was performed using a $\mathrm{SYBR}^{\circledR}$ Green assay (Takara Biotechnology Co., Ltd.) on a CFX96 PCR machine (Bio-Rad Laboratories, Inc.), according to the manufacturer's kit and PCR machine instructions. The thermocycling conditions were as follows: Pre-denaturation at $95^{\circ} \mathrm{C}$ for $30 \mathrm{sec}$; followed by 45 cycles of denaturation at $95^{\circ} \mathrm{C}$ for $5 \mathrm{sec}$, annealing at $60^{\circ} \mathrm{C}$ for $30 \mathrm{sec}$ and extension at $65^{\circ} \mathrm{C}$ for $1 \mathrm{~min}$. GAPDH was used as the endogenous control, and the mRNA expression of CDH11 was analyzed using the $2^{-\Delta \Delta \mathrm{Cq}}$ method (15). The primers used were as follows: CDH11 forward, 5'-CCCAGTACACGTTGATGCCT-3' and reverse, 5'-GACGTTCCCACATTGGACCT-3'; GAPDH forward, 5'-CTTTGGTATCGTGGAAGGACTC-3' and reverse, 5'-GTA GAGGCAGGGATGATGTTCT-3' (Sangon Biotech Co., Ltd.).

Immunohistochemical analysis. Tissues fixed with $4 \%$ paraformaldehyde at room temperature for $12 \mathrm{~h}$ were embedded in paraffin, and a series of $4-\mu \mathrm{m}$ sections were prepared. Sections were incubated at $60^{\circ} \mathrm{C}$ for $20 \mathrm{~min}$, deparaffinized in xylene at room temperature for $25 \mathrm{~min}$ and rehydrated in a descending ethanol series, prior to incubation in $3 \% \mathrm{H}_{2} \mathrm{O}_{2}$ at room temperature for $10 \mathrm{~min}$ to inhibit endogenous peroxidase activity. Nonspecific binding was blocked with $5 \%$ goat serum (BIOSS) at room temperature for $20 \mathrm{~min}$, and the sections were incubated with a rabbit anti-human CDH11 antibody (1:50; cat. no 6444R; BIOSS) overnight at $4^{\circ} \mathrm{C}$. The next day, the sections were incubated with a HRP conjugated goat anti-rabbit IgG $(1: 1,000$; cat. no. $40295 \mathrm{G}$; BIOSS $)$ at $37^{\circ} \mathrm{C}$ for $45 \mathrm{~min}$ and stained with diaminobenzidine reagent (DAB) for $4 \mathrm{~min}$ at room temperature. Five fields were randomly selected under a light microscope for scoring (magnification, $\mathrm{x} 100)$. Staining intensity scoring criteria were as follows: 0 points, no staining; 1 point, light yellow; 2 points, brownish yellow; 3 points, brown. Staining range scoring criteria were as follows: 0 points, $<5 \%$; 1 point, $5-25 \%$; 2 points, $26-50 \%$; 3 points, $51-75 \% ; 4$ points, $>75 \%$. The total score was the sum of the staining intensity and range, and a total score $\geq 4$ points was considered as high expression.

Gene Expression Profiling Interactive Analysis (GEPIA) and UALCAN analysis. GEPIA (http://gepia.cancer-pku.cn), an onlinecancer microarray database, was used to analyze the differences in CDH11 expression in 408 GC samples from TCGA and 211 normal samples from TCGA and GTEx (16). The cut-off P-value and $\log _{2}$ [fold-change (FC)] were defined as 0.01 and 1, respectively. UALCAN (http://ualcan.path.uab. edu) is an interactive web resource for analyzing cancer transcriptome data from TCGA (17). The expression of CDH11 in GC samples was analyzed based on disease state (cancer or normal), TNM stage, sex, age, tumor grade, histological subtype and Helicobacter pylori infection status.

Kaplan-Meier plotter and online survival analysis. Kaplan-Meier Plotter (http://kmplot.com), an online cancer microarray database containing gene expression profiles and survival data from 876 patients with GC, was used to analyze the effects of CDH11 on OS and progression-free survival (PFS) (18). Patients at different stages were divided into a high and a low expression group according to the automatically selected best cut-off to assess the OS and PFS.

MethHC and cBioPortal. MethHC (http://methhc.mbc.nctu. edu.tw), a database of DNA methylation and gene expression in human cancer, was used to compare the average methylation level of the CDH11 promoter in GC samples and matched normal samples (19). A total of 478 stomach adenocarcinoma samples from the cBioPortal database (http://www.cbioportal. org) were used to analyze the association between CDH11 mRNA expression and DNA methylation and copy-number alterations (20).

Search Tool for the Retrieval of Interacting Genes/Proteins (STRING), Kyoto Encyclopedia of Genes and Genomes (KEGG) and Gene Ontology (GO) analyses. STRING (http://string-db.org), a database of known protein-protein interactions, was used to predict proteins closely associated with CDH11. The minimum required interaction score and maximum number of interactors on the 1st shell were defined as 0.7 and 50, respectively. Subsequently, pathway-enrichment analysis was performed for these proteins using KEGG 
(http://kobas.cbi.pku.edu.cn), and the maximum false discovery rate was defined as 0.05 (21). GO analysis was performed using the Database for Annotation, Visualization and Integrated Discovery (version 6.8; https://david.ncifcrf. gov/home.jsp), and the maximum adjusted P-value was defined as $\mathrm{P}<0.05$ (22).

Prediction of upstream transcription factors of the CDH11 gene. The UCSC Genome Browser (http://genome. ucsc.edu) was used to localize the CDS region of CDH11, and its upstream 2,000 bp fragment was considered to be the transcriptional promoter region of the CDH11 gene (23). JASPAR (http://jaspardev.genereg.net) was used to predict the transcription factors that may bind to the CDH11 promoter (24). Transcription factors that were highly expressed and positively associated with the expression of CDH11 in GC were further screened and considered as the upstream transcription factors of CDH11.

Statistical analysis. The RT-qPCR experiments were repeated three times, and the data were analyzed using SPSS 19.0 software (IBM Corp.). Data are presented as the mean \pm standard deviation. The differences in CDH11 mRNA expression between GC and paracancerous tissues from 30 patients with GC admitted to the First Affiliated Hospital of Chongqing Medical University were compared using the paired Student's t-test. The method for differential analysis from GEPIA was one-way ANOVA, using disease state (tumor or normal) as the variable for calculating differential expression. The method for differential analysis from UALCAN was independent sample t-test. The association between CDH11 protein expression levels and the clinicopathological parameters of patients with $\mathrm{GC}$ was examined using the $\chi^{2}$ test. Pearson correlation analysis was used to determine thecorrelation between mRNACDH11 expressionand the $\beta$-value of CDH11 methylation and CDH11 relative linear copy number, within the cBioPortal database. The effects of CDH11 on the prognosis of patients with GC was analyzed using the Kaplan-Meier survival plot and log-rank test. Multivariate Cox analysis was used to determine the ability of CDH11 to predict the prognosis of patients. $\mathrm{P}<0.05$ was considered to indicate a statistically significant difference.

\section{Results}

CDH11 is upregulated in GC and is associated with clinical parameters. The expression of CDH11 in GC tissues and normal gastric tissues was analyzed using the GEPIA and UALCAN databases. As demonstrated in Fig. 1A, in both the GEPIA and UALCAN databases, CDH11 was upregulated in GC tissues compared with normal gastric tissues, and the fold-changes were 5.7 and 3.2, respectively.

The association between CDH11 and pathological parameters was analyzed using the UALCAN database. CDH11 expression was significantly higher in stage II, III and IV GC tissues compared with that in stage I GC tissues and normal gastric tissues, whereas no significant differences in expression were detected between stage I GC tissues and normal tissues. CDH11 expression was higher in mucinous intestinal adenocarcinoma and diffuse adenocarcinoma compared with other histological subtypes. Among all tumor grades, grade 3 tumors exhibited the highest expression of CDH11. CDH11 expression was not significantly associated with sex (Fig. 1B), age or $H$. pylori infection (data not shown). These results suggested that CDH11 was significantly increased in GC, and increased CDH11 was associated with TNM stage, differentiation degree and tumor grade.

High expression of CDH11 as a prognosticmarker of $G C$. The prognostic significance of CDH11 was analyzed in 876 patients with GC using the Kaplan-Meier Plotter database. Patients with high CDH11 expression exhibited shorterOSandPFS times (27.5 and 17.2 months, respectively) compared with those with low CDH11 expression (99.4 and 80.1 months, respectively) (Fig. 2A).

The prognostic significance of CDH11 for patients with GC at different stages was further analyzed. In patients with stage III-IV GC, high CDH11 expression was associated with short OS time. In patients with stage II GC, high CDH11 expression exhibited a trend towards a short OStime (Fig. 2B). Patients with stage III GC with high expression of CDH11 exhibited shorter PFS time compared with those with low expression. In patients with stage II and IV GC, high CDH11 expression was mildly associated with shorter PFStimes compared with low expression (Fig. 2C). However, high CDH11 expression was associated with longer OS and PFS times in patients with stage I GC.

Associations between CDH11 expression, DNA methylation and copy number alterations in GC. The MethHC database was used to analyze the methylation status of CDH11 in GC tissues and normal gastric tissues. Consistent with findings by Sepulveda et al (13), the results of the present study demonstrated that the level of methylation was markedly increased in GC tissues compared with normal tissues (Fig. 3A). Although CDH11 expression was significantly negatively associated with promoter methylation in GC tissues, the correlation coefficient was only -0.21 , indicating a weak correlation (Fig. 3A). This may explain the increased CDH11 promoter methylation in GC tissues, which is not associated with lower CDH11 mRNA expression compared with normal gastric tissues.

The association between increased CDH11 expression in GC tissues and DNA copy number alteration was further analyzed. Data from the cBioPortal database suggested that DNA copy number alterations were not more prevalent in GC tissues compared with normal gastric tissues. Only 1 of 478 patients exhibited significant gene amplification. Furthermore, correlation analysis indicated no correlation between copy number values and CDH11 mRNA expression (Fig. 3B). These results suggested that $\mathrm{CDH} 11$ was not regulated at the DNA level to mediate its upregulation in GC tissues.

Identification of putative upstream regulatory molecules of $C D H 11$. The promoter sequence of CDH11 was acquired from UCSC, and the transcription factors that could potentially bind to the promoter sequences in vertebrates were analyzed using the JASPAR database. A total of 342 transcription factors were selected, and their expression patterns were analyzed. A total of 67 upregulated transcription 

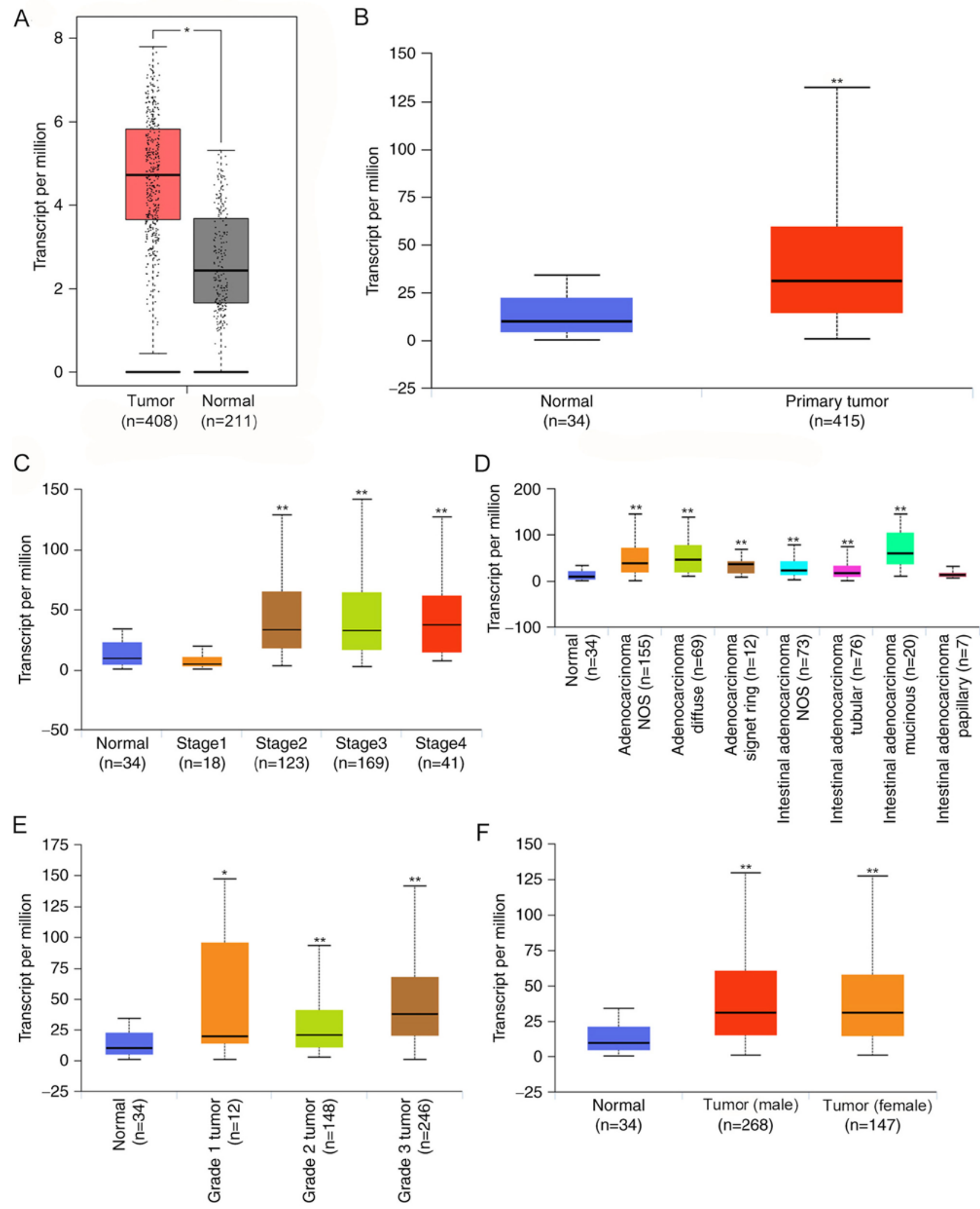

Figure 1. CDH11 expression in GC and its association with clinical parameters. (A) GEPIA and (B) UALCAN databases were used to analyze the differences in CDH11 expression between GC and normal gastric tissues. GEPIA included 408 GC samples from TCGA database and 211 normal gastric samples from TCGA and GTEx databases. UALCAN included 415 GC samples and 34 normal gastric samples from TCGA database. Association between CDH11 expression and clinical parameters including (C) Tumor-Node-Metastasis stage, (D) histological subtypes, (E) tumor grade and (F) sex. GC, gastric cancer; T, tumor tissue; N, normal gastric tissue CDH11, cadherin 11; GEPIA, Gene Expression Profiling Interactive Analysis; TCGA, The Cancer Genome Atlas; STAD, stomach adenocarcinoma. ${ }^{*} \mathrm{P}<0.05,{ }^{* *} \mathrm{P}<0.01$ vs. the normal group.

factors in GC (data obtained from the GEPIA database) were identified. Of these 67 transcription factors, nine were positively associated with CDH11 mRNA expression, as follows: Nuclear factor IA (NFIA), runt-related transcription 

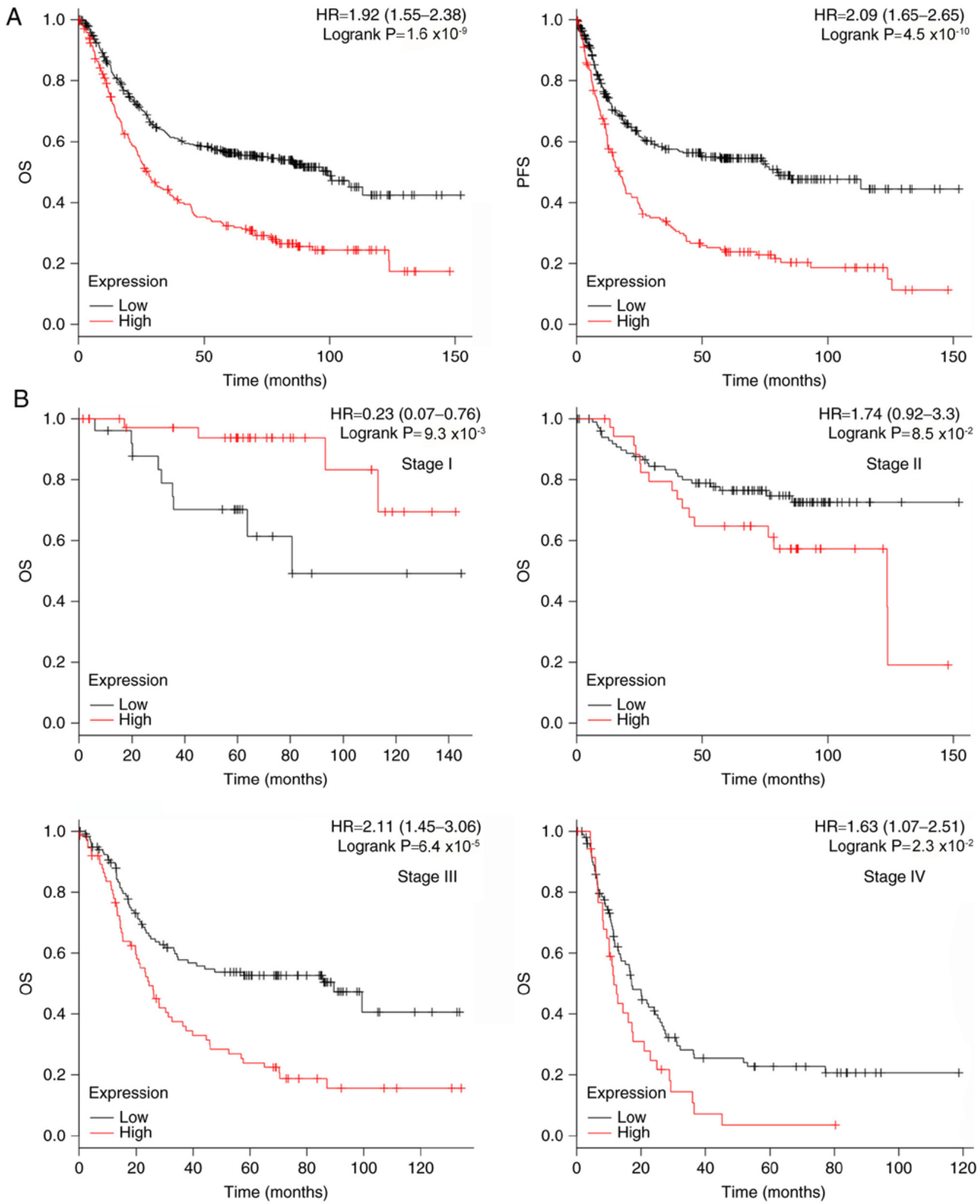

Figure 2. Increased CDH11 expression indicates a poor prognosis in advanced GC. (A) Analysis of the OS and PFS of patients with GC at all stages according to CDH11 mRNA expression levels. (B) Analysis of the OS of patients with GC from stage I to IV.

factor 2 (RUNX2), myocyte enhancer factor 2C (MEF2C), runt-related transcription factor 1 (RUNX1), lymphoid enhancer-binding factor 1 (LEF1), nuclear factor IX (NFIX), transcription factor 4 (TCF4), paired related homeobox 1 (PRRX1) and ETS proto-oncogene 1 (ETS1) (data obtained from the GEPIA database; Fig. 4). Thus, it was speculated that these nine transcription factors may mediate the upregulation of CDH11 in GC.

Potential molecular mechanism by which CDH11 promotes $G C$. A total of 45 proteins associated with $\mathrm{CDH} 11$ were identified using the STRING database (Fig. 5A) (http://string-db. 
C
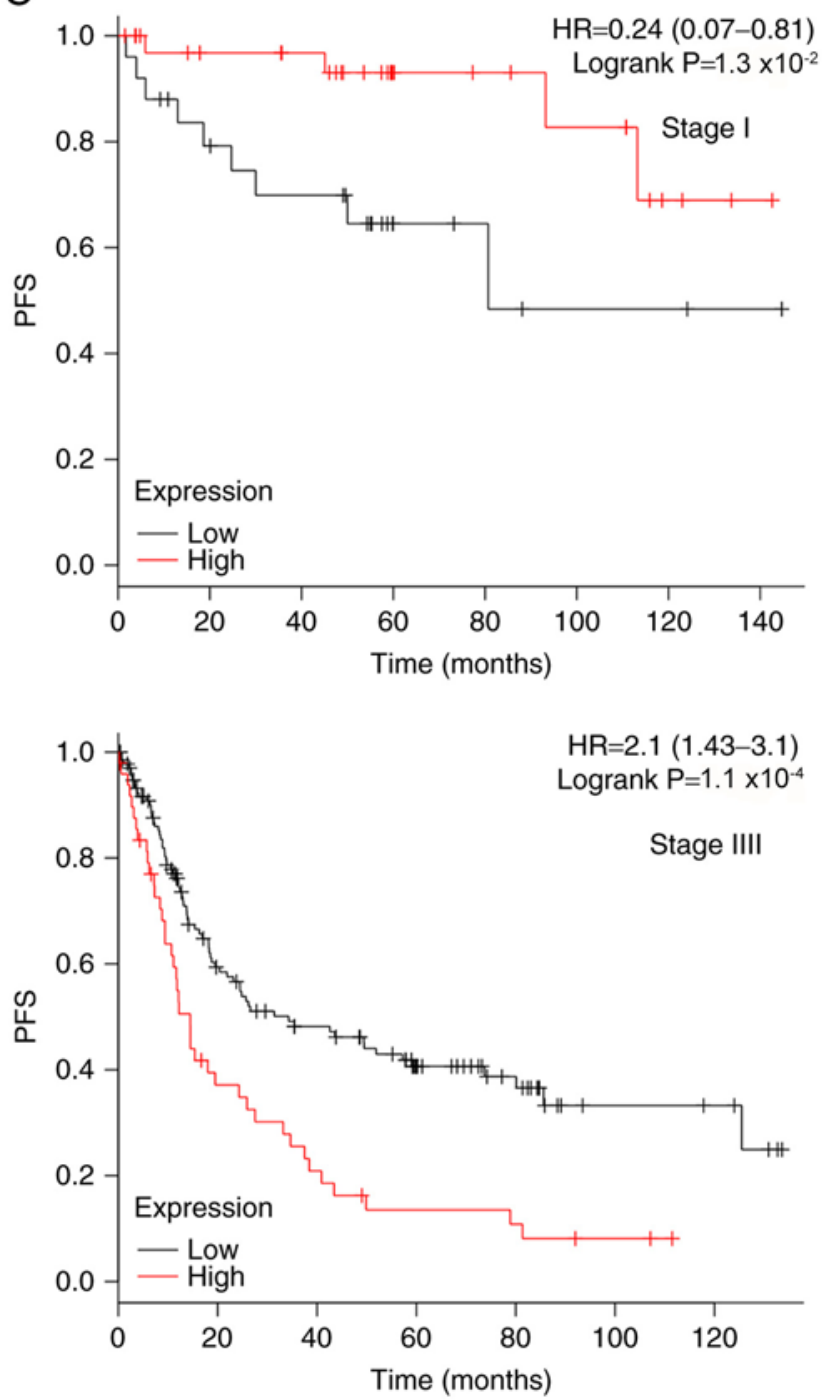
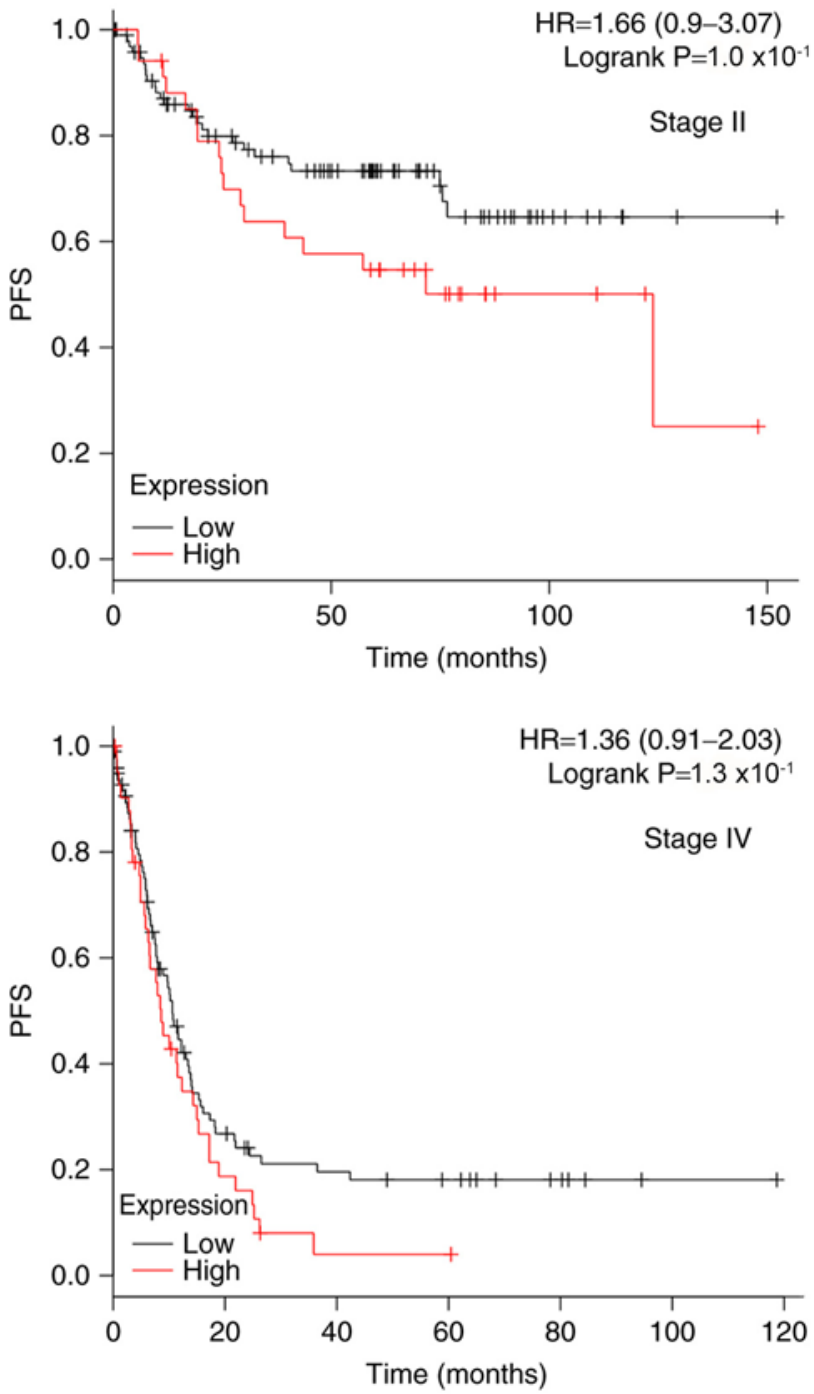

Figure 2. Continued. Increased CDH11 expression indicates a poor prognosis in advanced GC. (C) The PFS of patients with GC stage I to IV according to CDH11 mRNA expression levels. All data were derived from the Kaplan-Meier Plotter database. GC, gastric cancer; CDH11, cadherin 11; OS, overall survival; PFS, progression-free survival.

org) (25). GO analysis revealed that most of these proteins were involved in cell adhesion, extracellular matrix recombination and cell movement (Fig. 5B). KEGG enrichment analysis demonstrated that these proteins were enriched in various cancer signaling pathways such as 'pathways in cancer' (10 proteins), 'PI3K-Akt signaling pathway' (8 proteins), 'HIF-1 signaling pathway' (5 proteins), 'mTOR signaling pathway' (5 proteins), 'Jak-STAT signaling pathway' (5 proteins) and 'VEGF signaling pathway' (4 proteins) (Fig. 5C). These results suggested that CDH11 promoted GC progression by interacting with cell motility or adhesion proteins and by activating the downstream cancer-associated signaling pathways.

Validation of CDH11 expression and prognostic effectin a local cohort of patients with GC. The mRNA expression levels of CDH11 in $30 \mathrm{GC}$ tissues and matchedparacancerous tissues from the First Affiliated Hospital of Chongqing Medical University were detected by RT-qPCR. In 23 patients (76.7\%), the mRNA expression of CDH11 was higher in GC tissues compared with paracancerous tissues. The average
CDH11 mRNA expression in cancer tissues (mean $\Delta \mathrm{Ct}, 5.56$ ) was 4.03 -fold higher compared with that in paracancerous tissues (mean $\Delta \mathrm{Ct}, 7.25$ ) (Fig. 6A). These results indicated that the expression of CDH11 mRNA in GC tissues was significantly higher compared with adjacent tissues. The expression of the CDH11 protein in 82 patients with GC was further detected by immunohistochemistry. As demonstrated in Fig. 6B and C, CDH11 staining was mainly detected in the cytoplasm, with lower staining in the cell membrane (the negative control is presented in Fig. S1). Positive staining for the $\mathrm{CDH} 11$ protein was observed in $61 \mathrm{GC}$ tissues $(74.39 \%)$ in 82 patients (staining score $\geq 4$ ), and in only 27 (31.7\%) paracancerous tissues. The staining score (mean score, 4.69) in GC tissues was also significantly higher compared withparacancerous tissues (mean score, 2.44). High CDH11 expression was associated with poor differentiation and a late stage (Table I). Further analysis revealed that the expression of the CDH11 protein in patients with stage III and IV GC was higher compared with that in patients with stage I and II GC (5.35 vs. 4.07 , respectively; Fig. $6 \mathrm{C})$. These results were 
A

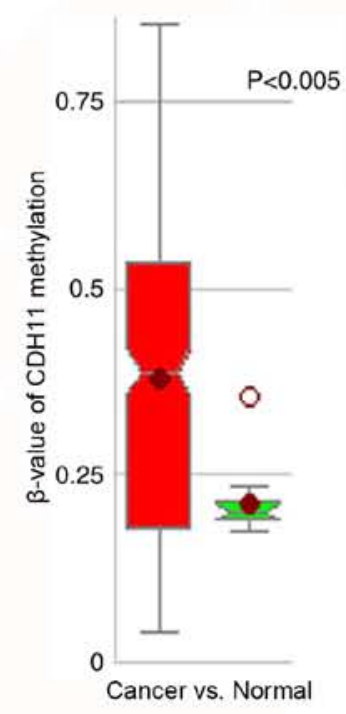

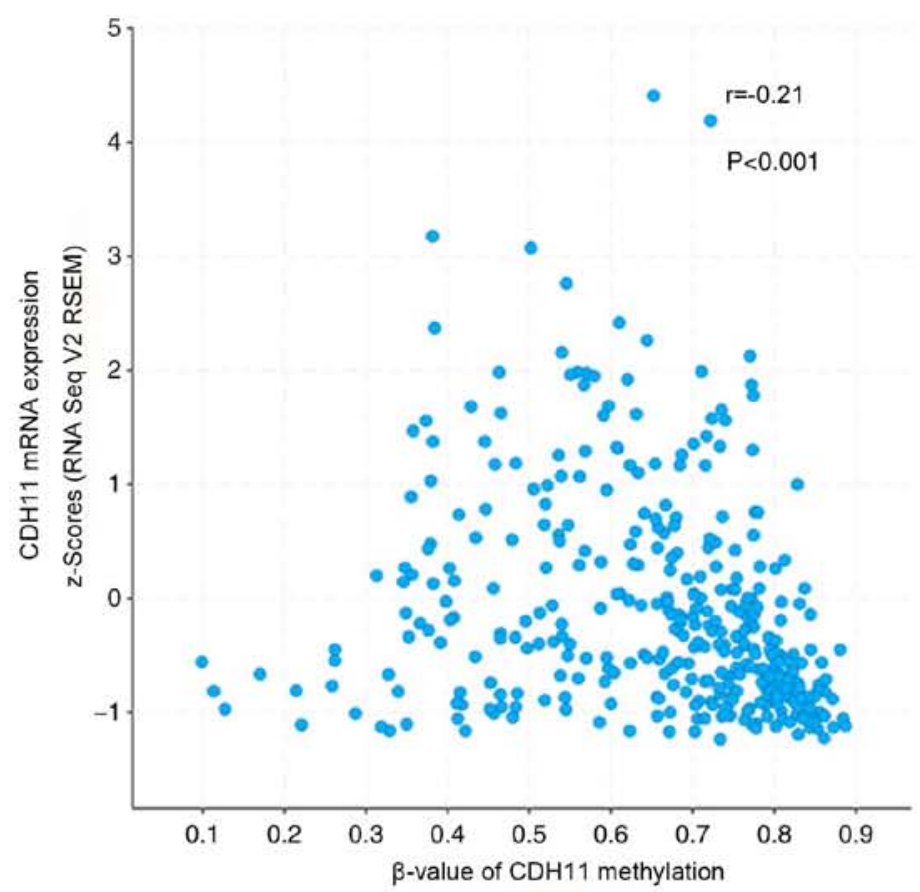

B

Cancer type detailed ||||||||||||||||||||||||||||||||||||||||||||||||||||||||||||||||||||||||

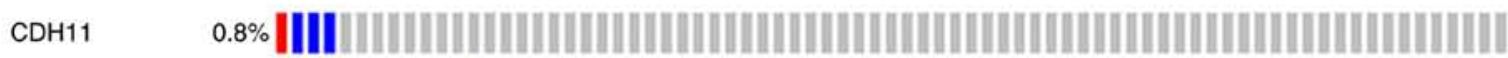

Genetic alteration \Amplification Deep deletion No alterations - Not profiled

Cancer type detailed Diffuse type stomach adenocarcinoma Mucinous stomach adenocarcinoma \Papillary stomach adenocarcinoma

|Signet ring cell carcinoma of the stomach |Stomach adenocarcinoma | Tubular stomach adenocarcinoma

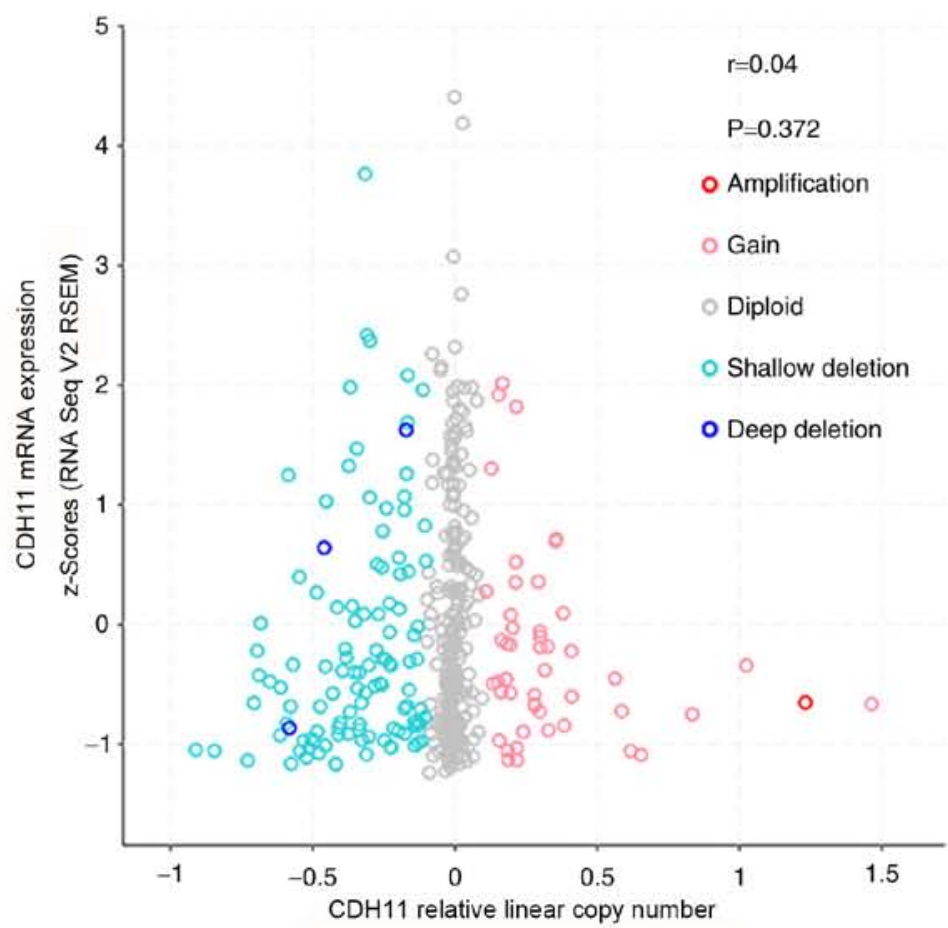

Figure 3. CDH11 mRNA expression is not attributed to DNA methylation or copy-number alterations. (A) The methylation level of the CDH11 promoter in gastric cancer and normal gastric tissues was determined, and its association with CDH11 mRNA expression was analyzed in the MethHC database. (B) Oncoprint in cBioPortal demonstrated the proportion and distribution of samples with alterations in CDH11. Plots in cBioPortal analyzed the correlation between CDH11 mRNA expression and relative linear copy number values. CDH11, cadherin 11. 


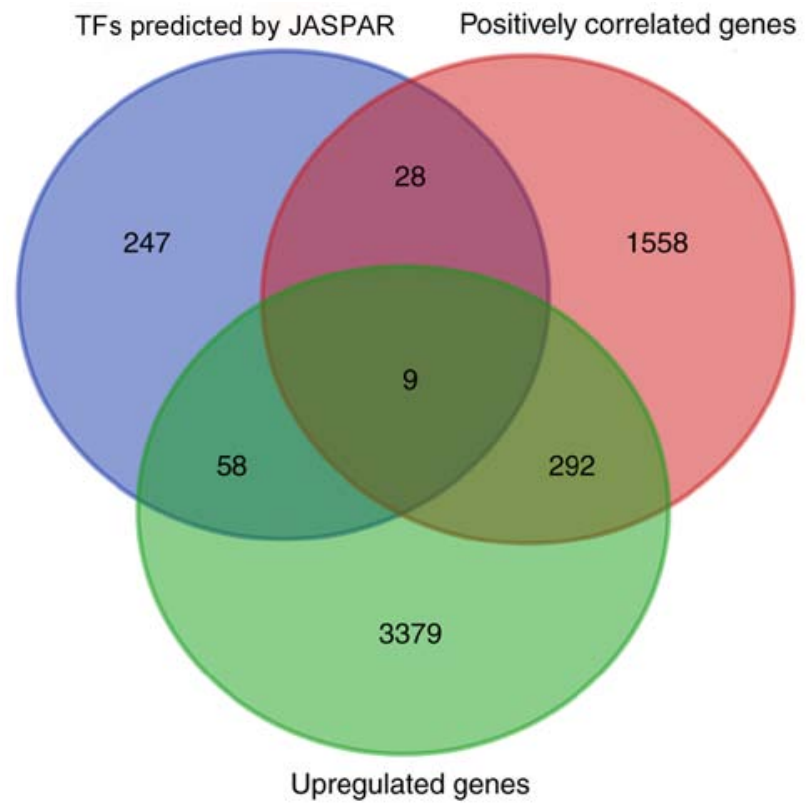

Figure 4. Putative transcription factors involved in CDH11 upregulation. The promoter sequence of $\mathrm{CDH} 11$ was obtained from the UCSC database, and the transcription factors capable of binding to the promoter sequence were predicted by the JASPAR database. A total of 9 TFs (NFIA, RUNX2, MEF2C, RUNX1, LEF1, NFIX, TCF4, PRRX1 and ETS1) were upregulated in gastric cancer tissues and positively associated with CDH11 expression. CDH11, cadherin 11; TFs, transcription factors.

consistent with the RT-qPCR data, suggesting that CDH11 expression was increased in GC tissues and may be involved in the progression of GC.

High CDH11 protein indicates a poor prognosis for patients with GC in the local cohort. The prognostic value of CDH11 was investigated in the 82 patients with GC from the First Affiliated Hospital of Chongqing Medical University. The median OS time of patients with GC and high expression of CDH11 was 28.6 months (Fig. 7A), and the median PFS time was 18.4 months, which were significantly shorter compared with patients with GC and low expression of CDH11 (OS time, 68.1 months; PFS time, 34.5 months) (Fig. 7B). Univariate analysis demonstrated that OS time was significantlyassociated with histological grade $(\mathrm{P}<0.001)$, nodal invasion $(\mathrm{P}=0.042)$, distantmetastasis $(\mathrm{P}=0.001)$, TNM stage $(\mathrm{P}<0.001)$ and $\mathrm{CDH} 11$ expression $(\mathrm{P}=0.017)$ (Table II). PFS time was significantlyassociated withhistological grade $(\mathrm{P}=0.001)$, distantmetastasis $(\mathrm{P}=0.005)$, TNM stage $(\mathrm{P}=0.008)$ and $\mathrm{CDH} 11$ expression $(\mathrm{P}=0.038)$ (Table III). However, the association between high CDH11 and OS and PFS wasnot significant after adjusting for otherprognostic markers in the multivariate analysis. These results indicated that $\mathrm{CDH} 11$ was associated with a shorter OS and PFS times in patients with GC, although high $\mathrm{CDH} 11$ expression was not an independent prognostic factor.

\section{Discussion}

In the present study, the upregulation of CDH11 in GC was demonstrated, and high expression of CDH11 was associated
Table I. Association between CDH11 and clinicopathological characteristics of patients with gastric cancer.

\begin{tabular}{|c|c|c|c|c|c|}
\hline \multirow[b]{2}{*}{ Characteristic } & \multirow[b]{2}{*}{ Number } & \multicolumn{2}{|c|}{ CDH11 } & \multirow[b]{2}{*}{$\chi^{2}$} & \multirow[b]{2}{*}{ P-value } \\
\hline & & - & + & & \\
\hline Sex & & & & 0.559 & 0.341 \\
\hline Female & 27 & 8 & 19 & & \\
\hline Male & 55 & 13 & 42 & & \\
\hline Age, years & & & & 0.479 & 0.489 \\
\hline$<60$ & 30 & 9 & 21 & & \\
\hline$\geq 60$ & 52 & 12 & 40 & & \\
\hline Histological grade & & & & 6.488 & $0.011^{\mathrm{a}}$ \\
\hline Grade 3 & 43 & 6 & 37 & & \\
\hline Grade 1 or 2 & 39 & 15 & 24 & & \\
\hline Tumor size, $\mathrm{cm}$ & & & & 0.013 & 0.911 \\
\hline$<5$ & 36 & 9 & 27 & & \\
\hline$\geq 5$ & 46 & 12 & 34 & & \\
\hline TNM stage & & & & 7.045 & $0.008^{\mathrm{a}}$ \\
\hline $1+2$ & 42 & 16 & 26 & & \\
\hline $3+4$ & 40 & 5 & 35 & & \\
\hline Vascular invasion & & & & 2.545 & 0.111 \\
\hline Absent & 64 & 19 & 45 & & \\
\hline Present & 18 & 2 & 16 & & \\
\hline Distant metastasis & & & & 0.088 & 0.767 \\
\hline No & 77 & 20 & 57 & & \\
\hline Yes & 5 & 1 & 4 & & \\
\hline
\end{tabular}

${ }^{\mathrm{a}} \mathrm{P}<0.05$. CDH11, cadherin 11; TNM, tumor-node-metastasis.

with the progression of GC. Using bioinformatics methods, the overexpression of CDH11 was demonstrated to be mainly attributed to transcriptional activation. Furthermore, it was revealed that CDH11 may exert its cancer-promoting effects by increasing cell movement and activating multiple downstream signaling pathways.

Abnormal expression of cadherins is associated with GC cancer progression. The loss or downregulation of E-cadherin leads to the translocation of $\beta$-catenin into the nucleus, which in turn promotes GC cell proliferation, drug resistance and metastasis through the WNT/ $\beta$-catenin signaling pathway (26). By contrast, $\mathrm{N}$-cadherin acts as an oncogene; high expression of $\mathrm{N}$-cadherin contributes to the loss of cell basal polarity and the disruption of cell adherens junctions, which promotes the movement of tumor cells from the primary lesion to the basement membrane, followed by the degradation of the extracellular matrix, breaking through the tissue barrier structure and eventually distant metastasis (27). However, the role of CDH11 in GC remains unclear.

Shibata et al (28) have demonstrated that CDH11 is highly expressed in gastric signet-ring cell carcinoma and surrounding fibroblasts, suggesting that CDH11 serves a key role in the formation of diffuse-type GC through cancer-stromal interactions. In addition, Sandoval-Bórquez et al (29) analyzed 19 pairs of GC and paracancerous samples and reported that 
Table II. Univariateanalysis and multivariateanalysis of prognostic factors for overall survival in gastric cancer.

\begin{tabular}{|c|c|c|c|c|c|c|}
\hline \multirow[b]{2}{*}{ Variable } & \multicolumn{3}{|c|}{ Univariate analysis } & \multicolumn{3}{|c|}{ Multivariate analysis } \\
\hline & HR & $95 \% \mathrm{CI}$ & P-value & HR & $95 \% \mathrm{CI}$ & $\mathrm{P}$-value \\
\hline Sex & 0.982 & $0.552-1.745$ & 0.950 & & & \\
\hline Age & 1.09 & $0.627-1.895$ & 0.759 & & & \\
\hline Histological grade & 3.325 & $1.825-5.695$ & $<0.001^{\mathrm{a}}$ & 3.122 & $1.752-5.564$ & $<0.001^{\mathrm{a}}$ \\
\hline Tumor size & 1.229 & $0.716-2.108$ & 0.455 & & & \\
\hline Nodal invasion & 1.924 & $1.023-3.616$ & $0.042^{\mathrm{a}}$ & & & \\
\hline Vascular invasion & 1.564 & $0.833-2.935$ & 0.164 & & & \\
\hline $\begin{array}{l}\text { Distantmetastasis a/Local/Youdao/Dict/ } \\
\text { Application/7.5.0.0/resultui/dict/? } \\
\text { keyword=metastasis }\end{array}$ & 7.082 & $2.348-21.363$ & $0.001^{\mathrm{a}}$ & 5.591 & $1.739-17.975$ & $0.004^{\mathrm{a}}$ \\
\hline TNM stage & 2.499 & $1.143-1.329$ & $0.001^{\mathrm{a}}$ & 2.124 & $1.195-3.788$ & $0.010^{\mathrm{a}}$ \\
\hline CDH11 expression & 2.236 & $1.157-2.425$ & $0.017^{\mathrm{a}}$ & & & 0.354 \\
\hline
\end{tabular}

${ }^{a} \mathrm{P}<0.05$. HR, hazard ratio; $\mathrm{CI}$, confidence interval; $\mathrm{CDH} 11$, cadherin 11; TNM, tumor-node-metastasis.

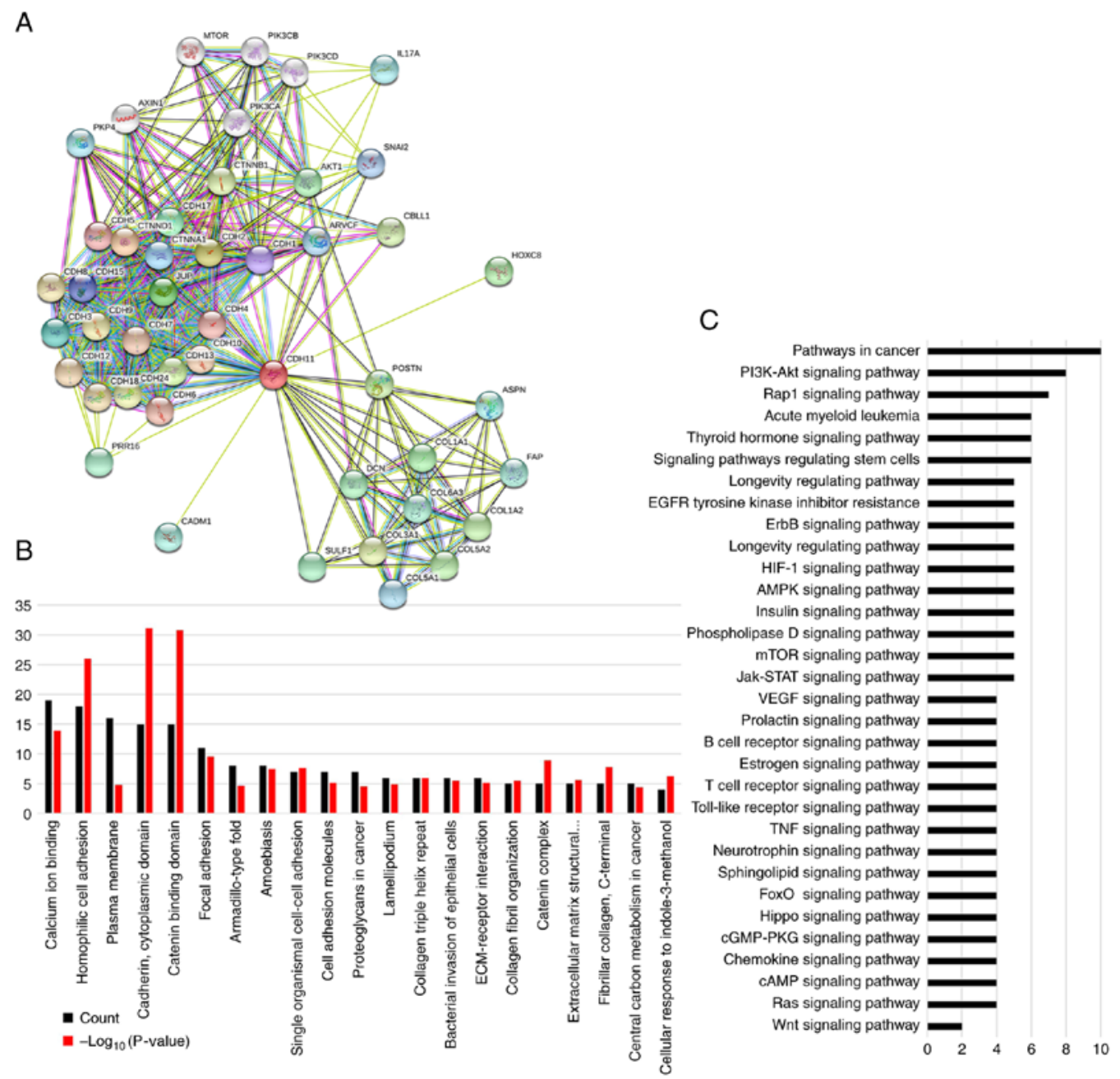

Figure 5. Potential molecular mechanism underlying CDH11 functions. (A) A total of 45 proteins closely interacting with CDH11 were identified using the STRING database. (B and C) Molecular function enrichment and pathway enrichment analysis of CDH11. CDH11, cadherin 11.

CDH11 mRNA was highly expressed in 17 of the samples. However, the aforementioned studies were limited by the lack of large sample analysis, and thus the role of CDH11 in GC needed further exploration. The present study used the GEPIA 

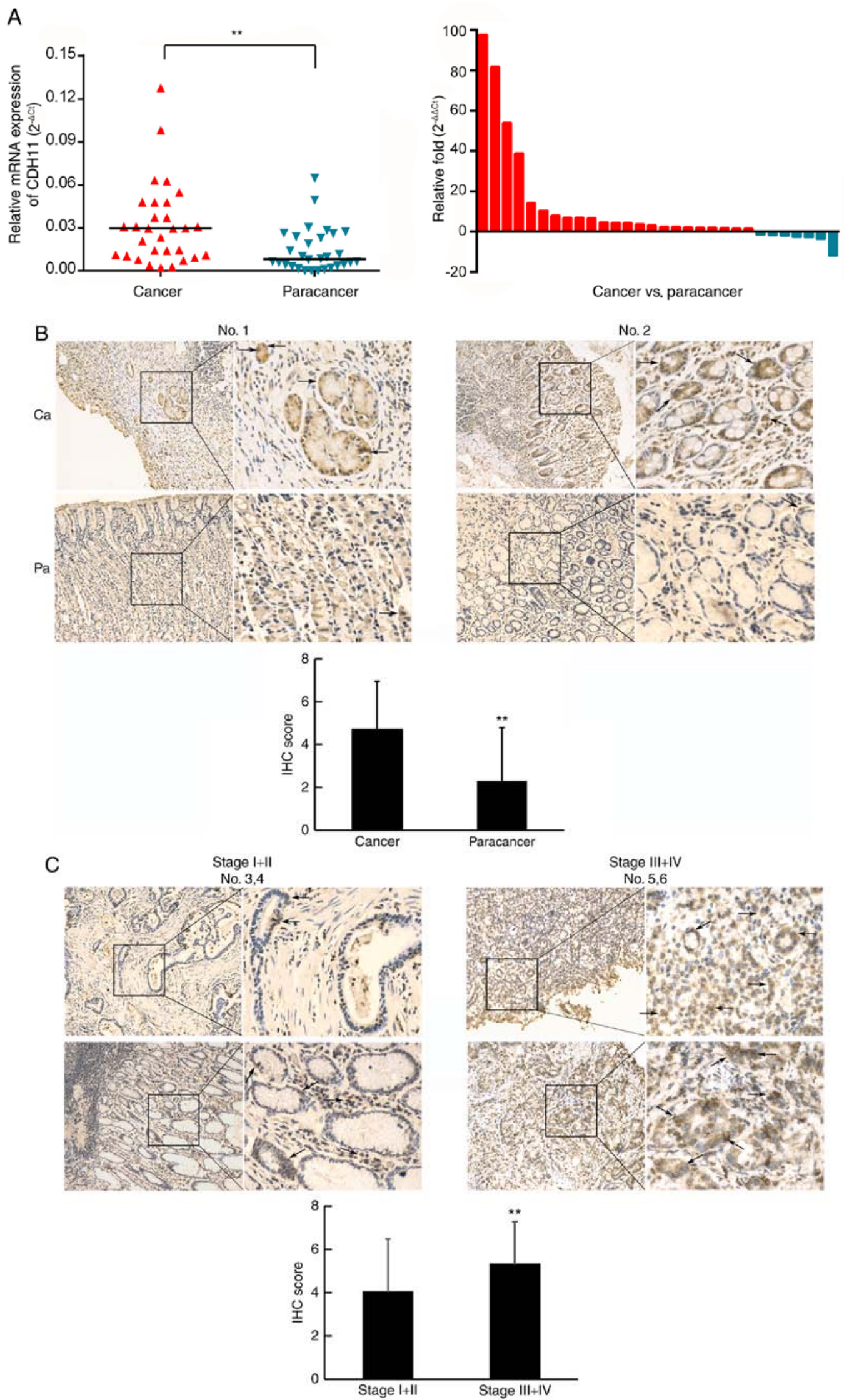

Figure 6. CDH11 is upregulated in GC. (A) The expression of CDH11 mRNA in frozen GC and paracancerous tissues of 30 patients with GC was detected by reverse transcription-quantitative PCR. The relative mRNA expression of CDH11 is expressed as $2^{-A C t}$ (left). The expression fold change of CDH11 mRNA in GC tissues to paracancerous tissues is expressed as $2^{-\Delta \Delta C t}$ (right). ${ }^{* *} \mathrm{P}<0.01$ vs. the non-cancer group $(\mathrm{n}=30)$. (B) The expression of the CDH11 protein in paraffin-embedded GC and paracancerous tissues of 82 patients with GC was detected by immunohistochemistry (magnification, $\mathrm{x} 100$ and $\mathrm{x} 400$ ). ${ }^{* *} \mathrm{P}<0.01 \mathrm{vs}$. the cancer group $(\mathrm{n}=82)$. (C) Representative CDH11 staining and average scores of cancer tissues in patients with stage I + II and stage III + IV GC (magnification, $\mathrm{x} 100$ and $\mathrm{x} 400) .{ }^{* *} \mathrm{P}<0.05$ vs. stage I + II group. The negative control is presented in Fig. S1. GC, gastric cancer; CDH11, cadherin 11; Ca, cancer tissue; $\mathrm{Pa}$, paracancerous tissue. 
Table III. Univariateand multivariateanalyses of prognostic factors for progression-free survival in gastric cancer.

\begin{tabular}{|c|c|c|c|c|c|c|}
\hline \multirow[b]{2}{*}{ Variable } & \multicolumn{3}{|c|}{ Univariate analysis } & \multicolumn{3}{|c|}{ Multivariate analysis } \\
\hline & HR & $95 \% \mathrm{CI}$ & P-value & HR & $95 \% \mathrm{CI}$ & P-value \\
\hline Sex & 0.989 & $0.58-1.686$ & 0.966 & & & \\
\hline Age & 1.125 & $0.638-1.985$ & 0.685 & & & \\
\hline Histological grade & 2.565 & $1.486-4.425$ & $0.001^{\mathrm{a}}$ & 2.518 & $1.447-4.383$ & $0.010^{\mathrm{a}}$ \\
\hline Tumor size & 1.136 & $0.673-1.918$ & 0.634 & & & \\
\hline Nodal invasion & 1.429 & $0.799-2.555$ & 0.228 & & & \\
\hline Vascular invasion & 1.508 & $0.823-2.764$ & 0.184 & & & \\
\hline Distantmetastasis & 4.509 & $1.569-12.9583$ & $0.005^{\mathrm{a}}$ & 3.805 & $1.261-11.484$ & $0.018^{\mathrm{a}}$ \\
\hline TNM stage & 2.058 & $1.212-3.496$ & $0.008^{\mathrm{a}}$ & 1.754 & $1.007-3.054$ & $0.047^{\mathrm{a}}$ \\
\hline CDH11 expression & 1.978 & $1.039-3.767$ & $0.038^{\mathrm{a}}$ & & & 0.379 \\
\hline
\end{tabular}

${ }^{\mathrm{a}}<0$.05. HR, hazard ratio; CI, confidence interval; TNM, tumor-node-metastasis; CDH11, cadherin 11 .

A

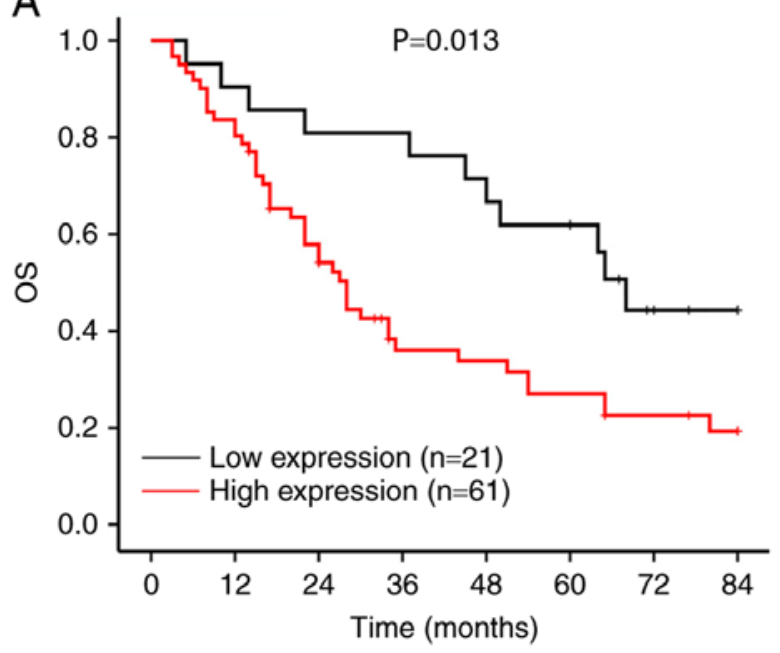

B

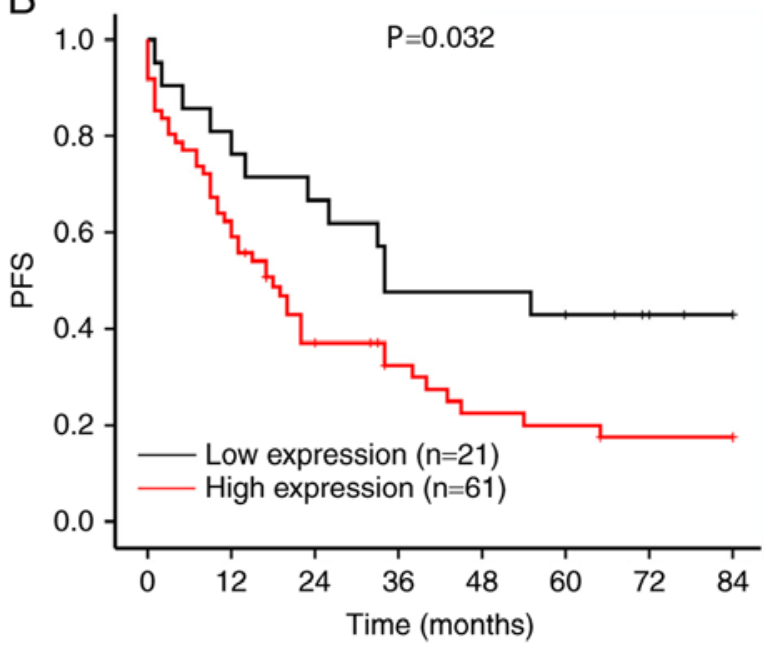

Figure 7. High expression of the CDH11 protein indicates a poor prognosis in patients with GC. (A and B) A total of 82 patients with GC admitted to the First Affiliated Hospital of Chongqing Medical University were divided into CDH11 high and low expression groups according to CDH11 immunohistochemistry scores, and the Kaplan-Meier survival curve was used to compare the differences in (A) OS and (B) PFS between the two groups. GC, gastric cancer; CDH11, cadherin 11; OS, overall survival; PFS, progression-free survival.

and UALCAN databases to analyze the data obtained from 408 and 415 patients with GC, respectively, and revealed that the expression of CDH11 was significantly higher in GC tissues compared with normal gastric tissues. No differences in CDH11 expression were observed between patients with stage I and normal tissues, which exhibited significantly lower CDH11 expression compared with patients with advanced GC. Follow-up survival analysis using the Kaplan-Meier Plotter database demonstrated that although high expression of CDH11 was associated with a shorter survival time in patients with advanced GC, it was also associated with a better prognosis in patients with stage I GC. A reasonable explanation for this finding may be that CDH11-mediated homologous adhesion promoted the formation of tight junction between cancer cells and cancer nests in early GC (7,30). In advanced GC, cancer cells infiltrated into the submucosa, where stromal cells also expressed CDH11. Therefore, CDH11 mediated heterologous adhesion between cancer cells and the stroma, thus promoting invasion and migration of GC cells.

To verify the CDH11 expression pattern in GC and its association with prognosis, specimens from the First Affiliated Hospital of Chongqing Medical University were used in the present study. The results demonstrated that the expression level of CDH11 was not only higher in GC tissues compared with paracancerous tissues, but also higher in advanced GC tissues compared with early GC. The survival analysis revealed that patients with high expression of CDH11 exhibited significantly shorter OS and PFS times compared with those with low CDH11 expression. Thus, the results of the present study suggested that $\mathrm{CDH} 11$ protein upregulation may be an indicator of poor prognosis in GC and indicated an oncogenic role of CDH11 in GC.

The mechanism underlying the upregulation of CDH11 in GC remains unclear. Previous studies have demonstrated 
that the CDH11 promoter is hypermethylated in bladder cancer, melanoma and head and necktumors (31). The present study analyzed the methylation status of CDH11 in GC and normal gastric tissues. Consistent with the findings by Sepulveda et al (13), the results of the present study demonstrated higher promoter methylation of the CDH11 gene in GC tissues compared with normal tissues, which contradicted the high mRNA expression of CDH11 in GC tissues. However, despite the high level of $\mathrm{CDH} 11$ promoter methylation in GC tissues, the correlation coefficient between the CDH11 methylation level and CDH11 mRNA expression level was only -0.21 , which was a weak correlation, suggesting that promoter methylation was not sufficient to reverse the upregulation of CDH11 expression caused by other reasons. The mechanism underlying the upregulation of CDH11 in GC is not clear. DNA copy number variation is a mechanism of gene upregulation; however, the copy number variation of CDH11 in GC tissues was only $0.8 \%$, and was not associated with the mRNA expression level of CDH11. These findings indicated that abnormal CDH11 expression in GC tissues was not attributed to a regulatory mechanism at the DNA level. Transcriptional activation is another mechanism by which genes are upregulated; a total of 342 transcription factors were predicted to be able to bind to the CDH11 promoter, of which nine (NFIA, RUNX2, MEF2C, RUNX1, LEF1, NFIX, TCF4, PRRX1, and ETS1) were upregulated and positively associated with the expression of CDH11 in GC. These nine transcription factors may be the putative regulatory molecules of CDH11, although this requires further functional validation.

CDH11 is a typical cell adhesion protein. One of its basic functions is to mediate cell-cell and cell-matrix junctions, thus regulating cell movement and the epithelial-mesenchymal transition $(32,33)$. In addition to its involvement in cell movement, $\mathrm{CDH} 11$ is a positive regulator of $\mathrm{NF}-\kappa \mathrm{B}$ signaling (34). Upregulated CDH11 in GC increases $N F-\kappa B$ activity and promotes the nuclear localization of $N F-\kappa B$ p 65 , leading to cell invasion and metastasis. In the present study, to further determine how CDH11 promoted GC progression, 45 molecules associated with CDH11 were analyzed using the STRING database, and the results demonstrated that these molecules were primarily involved in cell adhesion $(35,36)$ and migration $(37,38)$. KEGG analysis revealed that the identified molecules were enriched in multiple cancer-associated signaling pathways such as the PI3K-Akt (39), Wnt/ $\beta$-catenin (40) and HIF-1 signaling pathway (41). This suggested that $\mathrm{CDH} 11$ promoted the invasion and migration of GC cells by affecting the mechanical connections with other adhesion molecules and cytoskeletal proteins. However, the results of the present study indicated that $\mathrm{CDH} 11$ may also promote cell proliferation, drug resistance and metastasis by activating multiple downstream signaling pathways.

In conclusion, the present study demonstrated that CDH11 was upregulated in GC, and its upregulation may be used as a direct prognostic indicator of a negative outcome. Although the mechanism by which $\mathrm{CDH} 11$ promotes the progression of GC remains to be determined, the present study demonstrated that $\mathrm{CDH} 11$ upregulation may serve an oncogenic role in GC. Considering the anticancer effect of celecoxib in breast cancer cells (42), further studies on the function of CDH11 may provide a promising approach for the treatment of GC.

\section{Acknowledgements}

Not applicable.

\section{Funding}

No funding was received.

\section{Availability of data and materials}

The datasets generated and/or analyzed during the currentstudy are available from the corresponding author upon reasonable request.

\section{Authors' contributions}

QW and CL conceived and designed the experiments. YJ and XP conducted the experiments and analyzed the data. XP wrote the manuscript. All authors read and approved thefinal manuscript.

\section{Ethics approval and consent to participate}

The use of human tissue samples and experimental protocolswere approved by the Medical Ethics Review Committee of the First Affiliated Hospital of Chongqing Medical University andwritten informed consent was obtained from all patients [approvalno. (2012)649].

\section{Patient consent for publication}

Not applicable.

\section{Competing interests}

The authors declare that they have no competing interests.

\section{References}

1. Lordick F and Janjigian YY: Clinical impact of tumour biology in the management of gastroesophageal cancer. Nat Rev Clin Oncol 13: 348-360, 2016.

2. Shah MA: Gastrointestinal cancer: Targeted therapies in gastric cancer-the dawn of a new era. Nat Rev Clin Oncol 11: 10-11, 2014.

3. Kremmidiotis G, Baker E, Crawford J, Eyre HJ, Nahmias J and Callen DF: Localization of human cadherin genes to chromosome regions exhibiting cancer-related loss of heterozygosity. Genomics 49: 467-471, 1998.

4. Okazaki M, Takeshita S, Kawai S, Kikuno R, Tsujimura A, Kudo A and Amann E: Molecular cloning and characterization of OB-cadherin, a new member of cadherin family expressed in osteoblasts. J Biol Chem 269: 12092-12098, 1994.

5. Kimura Y, Matsunami H, Inoue T, Shimamura K, Uchida N Ueno T, Miyazaki T and Takeichi M: Cadherin-11 expressed in association with mesenchymal morphogenesis in the head, somite, and limb bud of early mouse embryos. Dev Biol 169: 347-358, 1995.

6. Hoffmann I and Balling R: Cloning and expression analysis of a novel mesodermally expressed cadherin. Dev Biol 169: 337-346, 1995.

7. Chu K, Cheng CJ, Ye X, Lee YC, Zurita AJ, Chen DT, Yu-Lee LY, Zhang S, Yeh ET, Hu MC, et al: Cadherin-11 promotes the metastasis of prostate cancer cells to bone. Mol Cancer Res 6: 1259-1267, 2008.

8. Huang CF, Lira C, Chu K, Bilen MA, Lee YC, Ye X, Kim SM, Ortiz A, Wu FL, Logothetis CJ, et al: Cadherin-11 increases migration and invasion of prostate cancer cells and enhances their interaction with osteoblasts. Cancer Res 70: 4580-4589, 2010. 
9. Assefnia S, Dakshanamurthy S, Guidry Auvil JM, Hampel C, Anastasiadis PZ, Kallakury B, Uren A, Foley DW, Brown ML, Shapiro L, et al: Cadherin-11 in poor prognosis malignancies and rheumatoid arthritis: Common target, common therapies. Oncotarget 5: 1458-1474, 2014

10. Nakajima G, Patino-Garcia A, Bruheim S, Xi Y, San Julian M, Lecanda F, Sierrasesumaga L, Müller C, Fodstad O and Ju J: CDH11 expression is associated with survival in patients with osteosarcoma. Cancer Genomics Proteomics 5: 37-42, 2008.

11. Rodríguez-Paredes M and Esteller M: Cancer epigenetics reaches mainstream oncology. Nat Med 17: 330-339, 2011.

12. Carmona FJ, Villanueva A, Vidal A, Muñoz C, Puertas S, Penin RM, Gomà M, Lujambio A, Piulats JM, Mesía R, et al: Epigenetic disruption of cadherin-11 in human cancer metastasis. J Pathol 228: 230-240, 2012

13. Sepulveda JL, Gutierrez-Pajares JL, Luna A, Yao Y, Tobias JW, Thomas S, Woo Y, Giorgi F, Komissarova EV, Califano A, et al: High-definition $\mathrm{CpG}$ methylation of novel genes in gastric carcinogenesis identified by next-generation sequencing. Mod Pathol 29: 182-193, 2016.

14. Washington K: 7th edition of the AJCC cancer staging manual: Stomach. Ann Surg Oncol 17: 3077-3079, 2010.

15. Livak KJ and Schmittgen TD: Analysis of relative gene expression data using real-time quantitative PCR and the 2(-Delta Delta C(T)) method. Methods 25: 402-408, 2001.

16. Tang Z, Li C, Kang B, Gao G, Li C and Zhang Z: GEPIA: A web server for cancer and normal gene expression profiling and interactive analyses. Nucleic Acids Res 45: W98-W102, 2017.

17. Chandrashekar DS, Bashel B, Balasubramanya SAH, Creighton CJ, Ponce-Rodriguez I, Chakravarthi BVSK and Varambally S: UALCAN: A portal for facilitating tumor subgroup gene expression and survival analyses. Neoplasia 19: 649-658, 2017.

18. Nagy Á, Lánczky A, Menyhárt O and Győrffy B: Validation of miRNA prognostic power in hepatocellular carcinoma using expression data of independent datasets. Sci Rep 8: 9227, 2018.

19. Huang W, Hsu S, Huang H, Sun Y, Chou C, Weng S and Huang H: MethHC: A database of DNA methylation and gene expression in human cancer. Nucleic Acids Res 43: D856-D861, 2015.

20. Gao J, Aksoy BA, Dogrusoz U, Dresdner G, Gross B, Sumer SO, Sun Y, Jacobsen A, Sinha R, Larsson E, et al: Integrative analysis of complex cancer genomics and clinical profiles using the cBioPortal. Sci Signal 6: 11, 2013.

21. Xie C, Mao X, Huang J, Ding Y, Wu J, Dong S, Kong L, Gao G, Li C and Wei L: KOBAS 2.0: A web server for annotation and identification of enriched pathways and diseases. Nucleic Acids Res 39: W316-W322, 2011.

22. Sherman BT and Lempicki RA: Systematic and integrative analysis of large gene lists using DAVID bioinformatics resources. Nat Protoc 4: 44, 2009.

23. Kent WJ, Sugnet CW, Furey TS, Roskin KM, Pringle TH, Zahler AM and Haussler D: The human genome browser at UCSC. Genome Res 12: 996-1006, 2002.

24. Stormo GD: DNA binding sites: Representation and discovery. Bioinformatics 16: 16-23, 2000.

25. Szklarczyk D, Gable AL, Lyon D, Junge A, Wyder S, Huerta-Cepas J, Simonovic M, Doncheva NT, Morris JH, Bork P, et al: STRING v11: Protein-protein association networks with increased coverage, supporting functional discovery in genome-wide experimental datasets. Nucleic Acids Res 47: D607-D613, 2019.

26. Yanaka Y, Muramatsu T, Uetake H, Kozaki K and Inazawa J: miR-544a induces epithelial-mesenchymal transition through the activation of WNT signaling pathway in gastric cancer. Carcinogenesis 36: 1363-1371, 2015.
27. Gao P, Xing AY, Zhou GY, Zhang TG, Zhang JP, Gao C, Li H and Shi DB: The molecular mechanism of microRNA-145 to suppress invasion-metastasis cascade in gastric cancer. Oncogene 32: 491-501, 2013.

28. Shibata T, Ochiai A, Gotoh M, Machinami R and Hirohashi S: Simultaneous expression of cadherin-11 in signet-ring cell carcinoma and stromal cells of diffuse-type gastric cancer. Cancer Lett 99: 147-153, 1996

29. Sandoval-Bórquez A, Polakovicova I, Carrasco-Véliz N, Lobos-González L, Riquelme I, Carrasco-Avino G, Bizama C, Norero E, Owen GI, Roa JC and Corvalán AH: MicroRNA-335-5p is a potential suppressor of metastasis and invasion in gastric cancer. Clin Epigenetics 9: 114, 2017.

30. Alimperti S and Andreadis ST: $\mathrm{CDH} 2$ and $\mathrm{CDH} 11$ act as regulators of stem cell fate decisions. Stem Cell Res 14: 270-282, 2015.

31. Lin YL, Gui SL and Ma JG: Aberrant methylation of CDH11 predicts a poor outcome for patients with bladder cancer. Oncol Lett 10: 647-652, 2015.

32. Yao J, Deng B, Zheng L, Dou L, Guo Y and Guo K: miR-27b is upregulated in cervical carcinogenesis and promotes cell growth and invasion by regulating CDH11 and epithelial-mesenchymal transition. Oncol Rep 35: 1645-1651, 2016.

33. Lee Y, Bilen MA, Yu G, Lin S, Huang C, Ortiz A, Cho H, Song JH, Satcher RL, Kuang J, et al: Inhibition of cell adhesion by a cadherin-11 antibody thwarts bone metastasis. Mol Cancer Res 11: 1401-1411, 2013.

34. Zhang JX, He WL, Feng ZH, Chen DL, Gao Y, He Y, Qin K, Zheng ZS, Chen C, Weng HW, et al: A positive feedback loop consisting of $\mathrm{C} 12$ orf59/NF- $\mathrm{KB} / \mathrm{CDH} 11$ promotes gastric cancer invasion and metastasis. J Exp Clin Canc Res 38: 164, 2019.

35. Ceteci F, Ceteci S, Karreman C, Kramer BW, Asan E, Götz R and Rapp UR: Disruption of tumor cell adhesion promotes angiogenic switch and progression to micrometastasis in RAF-driven murine lung cancer. Cancer Cell 12: 145-159, 2007.

36. Zhang Y, Li L, Zhu J, Kuang H, Dong S, Wang H, Zhang X and Zhou Y: In vitro observations of self-assembled ECM-mimetic bioceramic nanoreservoir delivering $\mathrm{rFN} / \mathrm{CDH}$ to modulate osteogenesis. Biomaterials 33: 7468-7477, 2012

37. Jia D, Jing Y, Zhang Z, Liu L, Ding J, Zhao F, Ge C, Wang Q, Chen T, Yao M, et al: Amplification of MPZL1/PZR promotes tumor cell migration through Src-mediated phosphorylation of cortactin in hepatocellular carcinoma. Cell Res 24: 204-217, 2014.

38. Moon H, Ju H, Chung SI, Cho KJ, Eun JW, Nam SW, Han K, Calvisi DF and Ro SW: Transforming growth factor- $\beta$ promotes liver tumorigenesis in mice via up-regulation of snail. Gastroenterology 153: 1378-1391, 2017.

39. Janku F, Yap TA and Meric-Bernstam F: Targeting the PI3K pathway in cancer: Are we making headway? Nat Rev Clin Oncol 15: 273-291, 2018.

40. Ordóñez-Morán P, Dafflon C, Imajo M, Nishida E and Huelsken J: HOXA5 counteracts stem cell traits by inhibiting Wnt signaling in colorectal cancer. Cancer Cell 28: 815-829, 2015.

41. Semenza GL: Targeting HIF-1 for cancer therapy. Nat Rev Cancer 3: 721-732, 2003.

42. Jendrossek V: Targeting apoptosis pathways by Celecoxib in cancer. Cancer Lett 332: 313-324, 2013.

This work is licensed under a Creative Commons

Attribution-NonCommercial-NoDerivatives 4.0 International (CC BY-NC-ND 4.0) License. 